\title{
Fragrante mostra de arte: de arte incômoda à cura simbólica
}

\author{
Carolina Cerqueira Correa ${ }^{1}$, Malando Vermelho ${ }^{2}$, Matheus Santana Cardoso Gouvêa ${ }^{3}$ e Lorraine \\ Pinheiro Mendes ${ }^{4}$
}

Resumo: A FRAGRANTE Mostra de Arte, realizada na cidade de Juiz de Fora, apresentou obras de negrxs artistas. Neste artigo buscamos analisar a exposição articulando três características específicas: a repetição, o conceito de "micro e macrobiografias" e a multiplicidade; propomos uma discussão sobre a produção africanabrasileira relacionada com um processo conjunto de cura simbólica.

Palavras-chave: FRAGRANTE, arte contemporânea, cura simbólica, arte africanabrasileira, decolonial

\section{Fragrante mostra de arte: from uncomfortable art to symbolic healing}

Abstract: FRAGRANTE Mostra de Arte, held in the city of Juiz de Fora, presented artworks by black artists. In this article we seek to analyse the exhibition articulating three specific characteristics: repetition, the concept of "micro and macro biographies" and multiplicity; we propose a discussion on African-Brazilian production related to a process of symbolic healing..

Keywords: FRAGRANTE, contemporary art, symbolic healing, Africanbrazilian art, decolonial

1 Artista visual e pesquisadora. Membro do Laroyê: Grupo de pesquisa em corpos, artes, culturas e linguagens decoloniais. Doutoranda em Artes, Cultura e Linguagens - PPGACL/UFJF. Universidade Federal de Juiz de Fora. E-mail: carolinaccerqueira@gmail.com. Lattes iD: http://lattes.cnpq.br/0849366342044876. Juiz de Fora, Brasil. ORCID: https://orcid.org/0000-0003-1562-840X

2 Artivista, Pesquisador e Educador. Membro do Laroyê: Grupo de pesquisa em corpos, artes, culturas e linguagens decoloniais. Mestrando em Artes, Cultura e Linguagens - PPGACL/UFJF. Universidade Federal de Juiz de Fora. E-mail: vermeverso@gmail.com. Lattes: http://lattes.cnpq.br/6281742233253000. Juiz de Fora, Brasil

3 Artista/Pesquisador. Membro do Laroyê: Grupo de pesquisa em corpos, artes, culturas e linguagens decoloniais. Mestre em artes cênicas pela Unirio na linha de Poéticas da cena e do texto teatral (2019). Universidade Federal do Estado do Rio de Janeiro E-mail: wayperformer@gmail.com. Lattes: http://lattes.cnpq.br/4337390750596205. Juiz de Fora, Brasil

4 Tatuadora e pesquisadora. Membro do Laroyê: Grupo de pesquisa em corpos, artes, culturas e linguagens decoloniais. Doutoranda em Artes, Cultura e Linguagens - PPGACL/UFJF. Universidade Federal de Juiz de Fora. E-mail: lorraine.artes@gmail.com. Lattes: http://lattes.cnpq.br/4921042522888362. Rio de Janeiro, Brasil. 
Ao entrar na Galeria "Heitor de Alencar", do Centro Cultural Bernardo Marcarenhas da cidade de Juiz de Fora, Minas Gerais, onde aconteceu, entre 5 e 13 de outubro de 2019, a exposição FRAGRANTE Mostra de Arte ${ }^{1}$ (Fig. 1), o espectador já se depara com o texto curatorial, escrito a mão na parede, onde se lê:

O desejo pela manifestação da expressão torna-se latente na plasticidade dos trabaIhos aqui apresentados, ecos ressoam múltiplas e complexas narrativas:

Prazer, ira, dor, celebração e luta

Corpos que insistem em aparecer e dizer seja em figurativas representações ou alegóricas ausências, ora com ares de ritos, crenças firmadas ou solapadas na história nacional.

Que nação? Quais corpos? Quem matou? Quem viveu?

Questões que se dissipam no ar feito fumaça mas são resgatadas igual memória impossíveis de ignorar como a fragrância de um perfume bom ou a de um corpo apodrecendo na esquina da rua de casa

Daqui você não passa

É tudo um grande flagrante o delito cometido fica a mercê

Flagradas dentro e fora daqui

Até onde o seu corpo pode ir? (Borges; Mancini, 2019)

A curadoria e as obras situam o observador em relação às poéticas da exposição. A questão "Até onde o seu corpo pode ir?" é respondida na medida em que o espaço expositivo, separado por fitas zebradas, apresenta a resposta que, como o texto de abertura, diz: "Daqui você não passa!". A exposição investiga, através da poesia, as possibilidades de existência de corpos não-brancos dentro de espaços institucionais no Brasil. Nas poéticas vigoram a denúncia, o contraste e uma análise do país da "democracia racial", onde a narrativa nacional frequenta, em certa medida, suas raízes múltiplas, mas responde com hipocrisia, violência e apagamento às vozes dos corpos pretos que relatam a sua experiência sem a necessidade de branda (ou branca) interlocução.

1 FRAGRANTE contou o trabalho de produção, expografia e curadoria de Luíza de Amorim, Luíso Camargo e Dayane Máximo. E ensaio fotográfico para divulgação da mostra. Direção de Arte: Luiso Camargo, produção: Luiza de Amorim, fotografia: MC Muxima, cenografia: Luiza de Amorim e João Paulo Leal, iluminação: Luiza de Amorim e João Paulo Leal, stylist: Gabriel Teles e Luíso Camargo, maquiagem: Lucas de Melo e Stefany Silva, cabelo: Jaqueline Souza, Melissa Domingues e Stefany Silva, staff: Matheus Cardoso. 

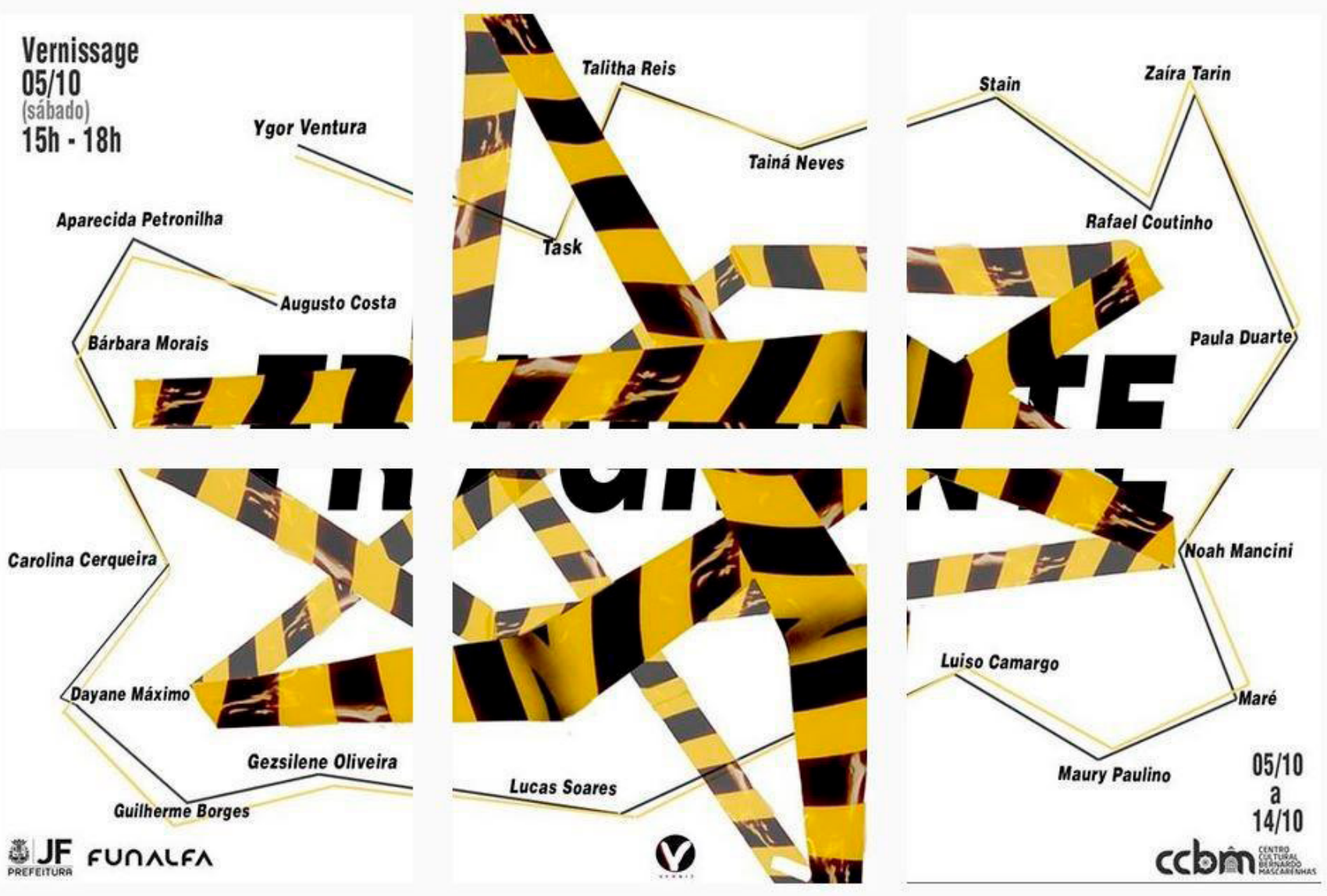

Figura 1 FRAGRANTE Mostra de Arte, arte divulgação disponível em: $<$ https://www. instagram.com/ vernizarte/>, acesso em: $28 \mathrm{fev}$. 2020
A mostra, aberta ao público por um período de apenas oito dias, ocorreu em um espaço expositivo de quatorze metros de comprimento e oito metros de largura dividido por uma parede ao centro. Reuniu 21 negrxs artistas: Augusto Henrique, Aparecida Petronilha, Bárbara Morais, Carolina Cerqueira, Dayane Máximo, Guilherme Borges, Gezsilene Oliveira, Lucas Soares, Luíso Camargo, Maury Paulino, Maré, Noah Mancini, Paula Duarte, Zaíra Tarin, Rafael Coutinho, Stain, Tainá Neves, Talitha Reis, Task, Ugo Soares e Ygor Ventura. A coletiva apresentou obras em diversas linguagens, como pintura, fotografia, escultura, instalação, cena curta e performance.

A FRAGRANTE Mostra de Arte seguiu o argumento da exposição Preto ao $C u b o^{2}$, realizada na Galeria Guaçuí, da Universidade Federal de Juiz de Fora, em 2018. Ambas exposições foram construídas exclusivamente por negrxs artistas, tratando de temas que atravessam as experiências de negritude no Brasil. 
De acordo com um dos curadores Guilherme Borges (1995) o título vem como referência a uma experiência olfativa:

A palavra "Fragrante" (e não "flagrante") dá o tema da exposição, determinada à partir de sua relação com a palavra "Fragrância", como referência à sensação de novo que o cheiro de verniz traz em uma clássica vernissage, mas também ao incômodo, como um forte odor, que se gera ao criar ruídos nas estruturas convencionais dos mecanismos sociais no momento em que o oprimido ocupa os mesmos espaços comuns ao opressor. (Borges apud Tribuna, 2019)

Dentro de um jogo semântico-político, "fragrante", ao nomear a exposição, ganha um sentido irônico, como se corpos negros ao entrarem em espaços antes negados, e atualmente acessado por poucos, revelassem alguma coisa perfumadamente desagradável. A ironia se apresenta no incômodo velado como algo perfumado, evidenciando contradições existentes na sociedade brasileira.

Conjuntamente com a definição expandida, a palavra-título da mostra também diz respeito a uma marca de africanização do português falado no Brasil. Socialmente estigmatizada como marcador de raça e classe, "fragrante" remete a uma variação de pronúncia da palavra "flagrante", disparando assim uma série de outras significações entre noções de "flagrar" ou "ser pego em flagrante". Quanto ao fator de africanização do português, a intelectual, antropóloga e professora Lélia Gonzalez (1935-1994) afirma que a língua falada no Brasil deveria se chamar "pretuguês":

É engraçado como eles gozam a gente quando a gente diz que é Framengo. Chama a gente de ignorante dizendo que a gente fala errado. E de repente ignoram que a presença desse " $r$ " no lugar do "I", nada mais é que a marca linguística de um idioma africano, no qual o "I" inexiste. [...] Ao mesmo tempo acham o maior barato a fala dita brasileira, que corta o erres dos infinitivos verbais, que condesa "você" em "cê", o "está" em "tá" e por aí afora. Não sacam que tão falando pretuguês. (Gonzalez, 1983, p.238).

O sistema da arte, refletindo a estrutura social, que no caso do Brasil é ainda fortemente marcada pela herança colonial escravocrata, classifica determinadas manifestações artísticas como "particularidades identitárias" de determinado grupo. Sendo assim, a herança negra é a escravidão? A vivência negra está na marca do discurso de sua própria exclusão? Artistas africanosbrasileiros contemporâneos estão contestando a narrativa imaginada que limita nossas existências. Narrativa que, baseada em nossos corpos, "identifica" uma suposta inferioridade, apaga histórias, visões de mundo e a insubmissão ao sistema colonial escravista. 
As poéticas desses artistas são atravessadas pelo vivido, pelo individual que encontra ressonância no coletivo e por repetições simbólicas.

\title{
Micro e Macrobiografias
}

Ao tratarmos das questões que vêm sendo trabalhadas na arte africanabrasileira contemporânea ao redor do país, e que, portanto, se fazem presentes na FRAGRANTE, temos Rosana Paulino (1967) e Eustáquio Neves (1955) como pioneiros na temática artística que tem fundação em uma perspectiva pessoal, mas que ecoa ao encontrar os espectadores e a poética de outros artistas (Santos, 2016).

Rosana tem seu foco principal de investigação a negra mulher dentro da sociedade brasileira. E sua obra "Parede de Memória", de 1994, por exemplo, toca os afetos particulares da artista, desde as fotografias familiares até os patuás que remetem a um amuleto que ficava na parede da sala da casa de infância de Paulino. Em suas palavras:

Eu resolvi pegar onze fotografias de família. Eu cheguei a montar o trabalho com 1.300 peças. Ou seja, tem a questão da multidão e do ignorar. Você ignora uma dessas pessoas na multidão, mas você não ignora 1.300 pares de olhos em cima de você. (Paulino, 2014)

Já o fotógrafo Eustáquio Neves em entrevista sobre suas fotografias diz:

\begin{abstract}
Esses personagens eu podia dizer que sou eu. Eu estou sempre falando de mim. Eu estou sempre falando da minha origem, de onde eu vim, das minhas questões, das questões de todas as pessoas negras, mas estou falando de mim ao mesmo tempo. E sempre gente do meu entorno: família, amigos, eu mesmo. A própria história, o próprio discurso me leva a isso. (Neves, 2019)
\end{abstract}

Voltando para dentro de si e pensando arte através de incômodos pessoais, os dois artistas arrematam suas obras direcionando a contemplação para os reflexos do racismo que atravessam as vidas negras, já que, como efeitos desse corpo racializado, nunca falamos de nossas vivências apenas como "eu", mas sempre enquanto "nós".

Responder continuamente pelo grupo tem efeitos negativos, mas no processo da cura simbólica tem efeitos positivos. Entendemos que os antídotos históricos e a cura não virão para um se não vierem para todos, já que o racismo existe e se perpetua não sob o efeito de ações individuais, mas sim 
sob elementos estruturais que mantém nossas instituições.

Na mesma linha de pensamento de Paulino e Neves, Guilherme Borges, com a obra Processo de Desmemorização III (Fig. 2), de 2019, utiliza uma fotografia antiga e através de intervenções, bordadas direto na foto, cobre os rostos das pessoas representadas com uma máscara ou com uma linha. O suporte pardo e os prendedores pretos de papel talvez remetem a idéia de arquivo. $E$, se assim for, o que fica arquivado são dissimulações, desculpas, borrões, e a pergunta: "Quem é a sua tataravó?".

Os pesquisadores Stuart Hauser (1938) e Eydie Kasendorf (1955), em um estudo realizado nos Estados Unidos, observam a formação, no âmbito familiar, de pessoas negras e brancas. Apesar de se tratar de uma pesquisa desenvolvida em outro país, alguns vínculos e informações sobre a memória das famílias negras e das brancas se estendem de forma similar no Brasil. A pesquisa aponta que a respeito do conhecimento do passado de indivíduos com ascendência européia, com frequência, há conhecimento da história de pelo menos uma geração anterior, tanto do lado da mãe quanto do pai. Alguns indivíduos conhecem vários avós, sabem de suas vidas e trabalho na Europa. Não há relutância nem desconforto em falar sobre eventos e figuras do passado. De fato, vários indivíduos com ascendência européia são extremamente orgulhosos de seus parentes, admirando suas posses e reputações. Os elementos desagradáveis que deveriam ter existido foram ofuscados pelas orgulhosas lembranças dos sujeitos e pelo abundante conhecimento factual do passado. Mais importante, os aspectos negativos de suas histórias não tinham peso suficiente para sugerir qualquer perturbação ou negação do passado (Hauser; Kasendorf, 1987).

Ao contrário de lembranças honrosas, como Clóvis Moura (1925) registra, os escravizados nem mesmo eram considerados cidadãos brasileiros, a saber, "no Brasil costumavam dizer que para o escravo são necessários três PPP: pau, pão e pano" (Malheiro apud Moura, p.73, 1988). Processo de Desmemorização III fala sobre a dureza da perda de laços familiares e culturais. Afinal, o que houve antes da marcada escravidão? E inclusive, o que houve após o 13 de maio de 1888? Talvez pela necessidade de preencher lacunas e os vazios do esquecimento histórico, o primeiro lugar onde muitos artistas africanosbrasileiros buscam respostas é em si mesmos. Investigando, através da poesia, seus próprios corpos, suas famílias e origens imediatas.

O outro trabalho de Borges em exibição na FRAGRANTE, com o título 
Figura 2

Guilherme Borges, Processo de Desmemorização

III e $8 \times 10$, colagem e objeto, s.d, 2019. Fotografia: MC Muxima.

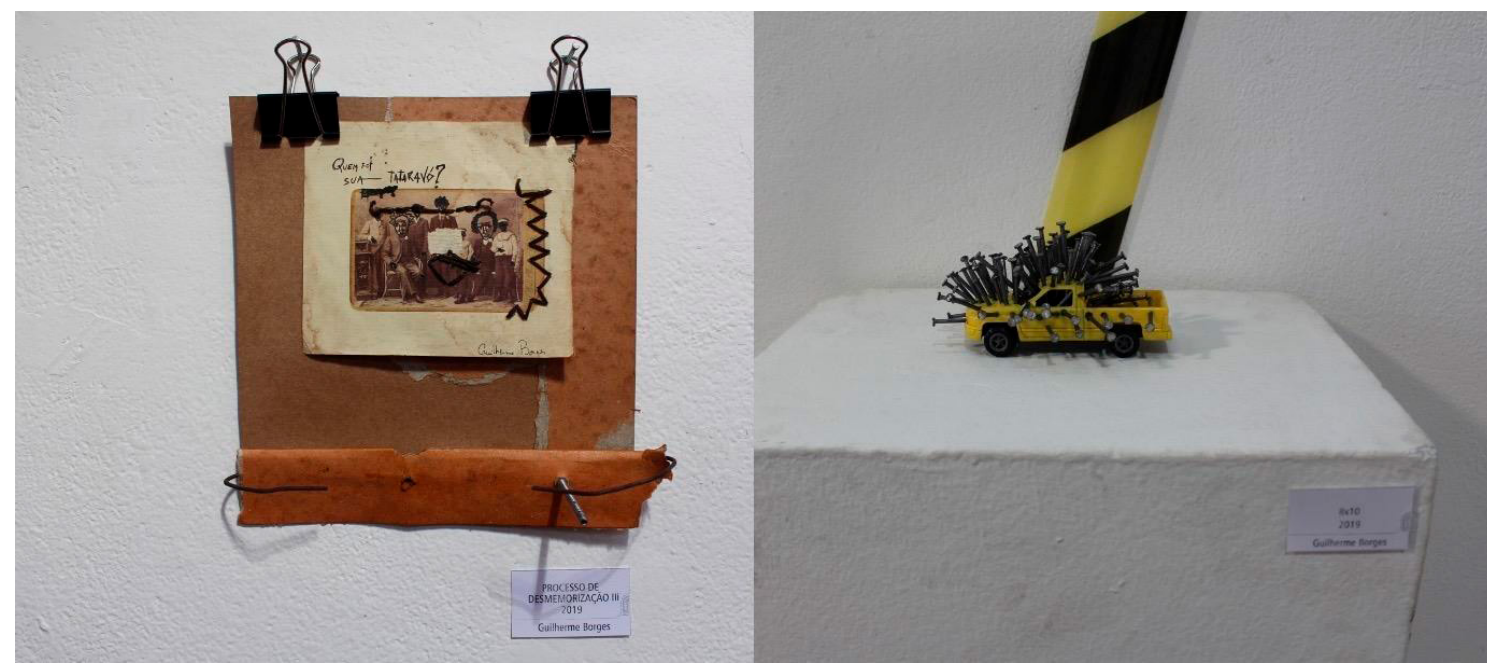

$8 \times 10$ (Fig. 2), de 2019, nos lembra de Evaldo dos Santos Rosa, assassinado na frente de sua esposa e filha, na cidade do Rio de Janeiro, após militares do exército dispararem "equivocadamente" oitenta tiros contra o carro da família negra que se dirigia a um chá de bebê em um dia domingo. O cientista político e ativista do movimento negro Márcio André dos Santos escreve, em uma matéria produzida para o Brasil de Fato:

O que justificaria fuzilar um carro com 80 tiros? [...] Seriam 'terroristas'? 'Inimigos do Estado'? [...] Fico aqui me perguntando o que queriam realmente matar com esses 80 tiros... Queriam matar um homem negro e sua família ou nossa humanidade inteira? (Dos Santos, 2019).

Outro lugar disparador de exasperadas ponderações é a visível insignificância de nossas vidas. São cruéis e desiguais as realidades experimentadas por pretos que levavam, e ainda levam, os nossos a morte, brutal, no dia-a-dia por "engano", onde esse "engano" pode ser entendido no limite que determina quem deve viver e quem deve morrer. $\mathrm{O}$ controle humano através da raça, ou seja do racismo, está atrelado a morte, isto é, a legitimidade do morrer de certos indivíduos, em sujeição do viver de outros. Assim a obra de Guilherme ao invocar raça, invoca junto com ela um sentimento de perda frente ao extermínio. $8 \times 10$ simboliza um medo do próximo alvo. Hoje Evaldo, amanhã quem?

A artista e pesquisadora Renata Felintos dos Santos (1978) singulariza as biografias que envolvem as poéticas negras:

Dos ateliês periféricos dos grandes centros urbanos às cidades do interior do país, emergem representações e entendimentos visuais acerca da história dos africanos no Brasil, mesclando registros que vão de pequenas conquistas individuais às gran- 
des violências coletivas. A essa forma de se trabalhar a arte considerando o aspecto íntimo e pessoal das vidas dos indivíduos artistas aos de ação grupal e política, denominamos de "microbiografias" e de "macrobiografias", isto é, estratégias visuais para a ampliação das percepções e entendimentos do ser negro ou negra, filtradas pela sensibilidade artística de seus produtores que, após dedicarem-se aos temas que mais Ihes tocam independente dos motivos que desencadeiam sentimentos e consciências, buscam pelas linguagens e expressões mais apropriadas para se dar visualidade, corpo a estas ideias, reflexões. (Santos, p.153, 2016)

Logo, levando em conta os conceitos de Renata Felinto como aglutinador para a análise de algumas das obras presentes na FRAGRANTE, percebemos como Borges, produzindo sua arte, transita pela micro e pela macrobiografia projetando incômodos em duas esferas, e possibilitando a ampliação do efeito das obras e suas leituras possíveis.

Figura 3 Lucas Soares, Série Daquilo que não está, mas se faz presente, óleo sobre metal, $60 \times 40 \mathrm{~cm}, 2019$,

Augusto Henrique, (Re)vendo o Banho de Sangue, acrílica sobre tela, $15 \times 30 \mathrm{~cm}, 2019$, fotografia MC Muxima.

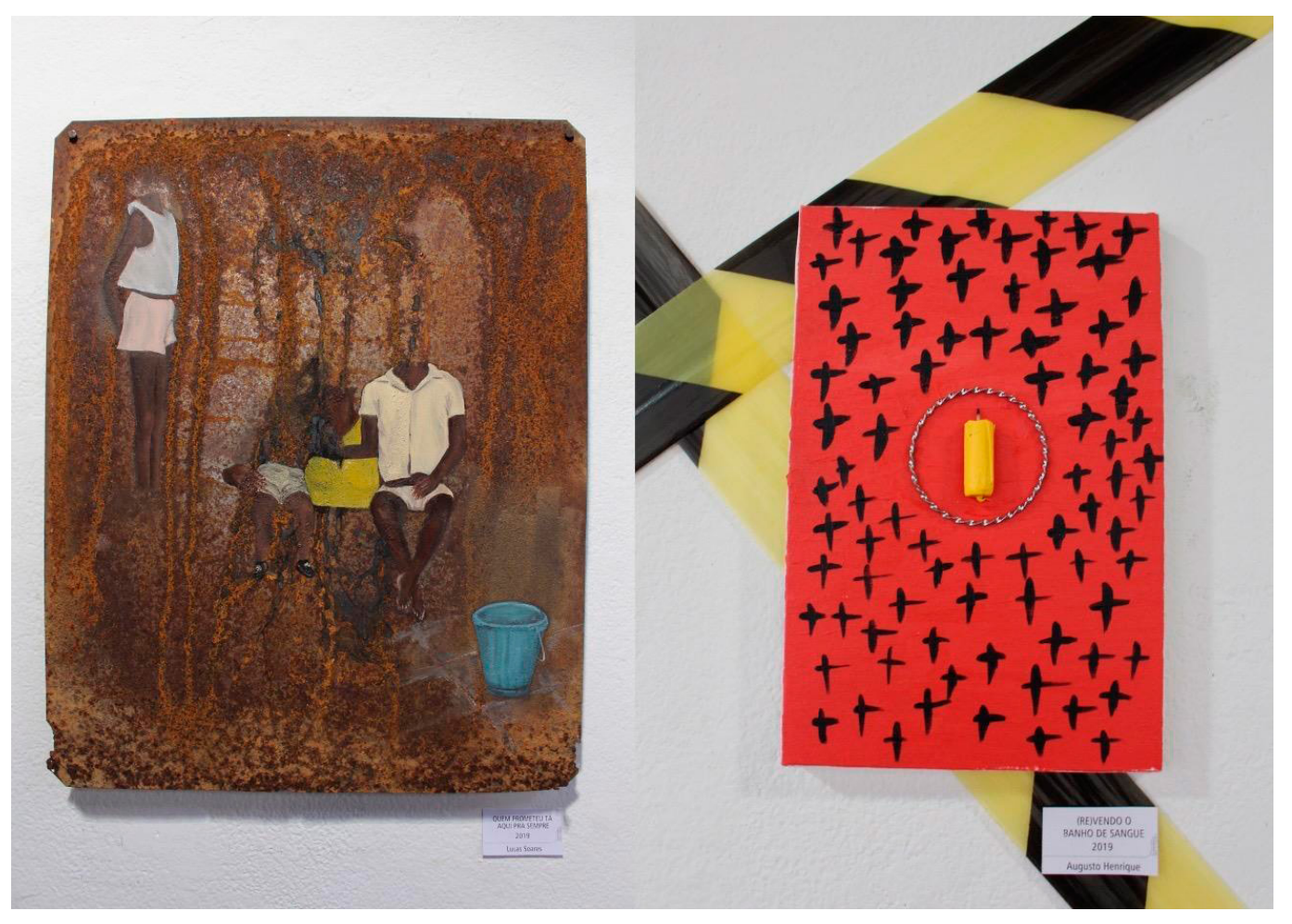

Continuando com os mesmos conceitos, a série de pinturas sobre metal, com o título Daquilo que não está aqui, mas se faz presente (Fig. 3), de 2019, de Lucas Soares (1996), novamente nos instiga a pergunta "Quem é?". Sobre o trabalho Soares diz:

Nessa série busco uma relação de rememoração e construção de narrativas a partir de fotos de famílias, tanto da minha como de outras; tendo como ponto de encontro de serem de pessoas desconhecidas à mim; e tendo como única semelhança por sermos negros." (Soares, 2019). 
Observando a obra de Soares, a vida contemporânea cotidiana, o jogo entre identidade e incógnita, o joão-ninguém, um jogo de mostrar e esconder, o zé-ninguém atravessam o pensamento. Com olhar atento, entre as ferrugens podemos crer identificar o contorno de um perfil ou um rosto silhuetado. A face humana, em recorrência, é coberta por um véu, por um simulacro. O artista, assim como Guilherme Borges, faz uso de fotografias para produzir suas imagens pictóricas. Essa série do artista nos remete às discussões relacionadas a representação da população negra, não apenas nas artes, mas no mercado de trabalho, na escola, num costumeiro lugar construído socialmente. A luta diária, alimentada pela imposição de uma rançosa marca visível da contínua servidão, persiste em um duo entre a sobrevivência e a tentativa de certificar os outros, e a nós mesmos, de que não somos a síntese da ameaça, ou seja, não somos vagabundos, criminosos ou violentos. (Barreto, 2018).

A obra de Lucas, criada a partir da família, passa a nos proporcionar uma reflexão sobre as circunstâncias similares que corpos pretos encontram em suas trajetórias cotidianas. E assim como Borges, a arte de Soares percorre caminhos entre as duas construções narrativas, a micro e a macro.

Já o artista Augusto Henrique (1993), manifestando nessa exposição características macrobiográficas, nos apresenta o trabalho ( $R e$ )vendo o Banho de Sangue (Fig.3), de 2019. Um trabalho de pintura acrílica sobre tela, com o fundo vermelho e as cruzes cristãs em preto representando massacre. Segundo o Atlas da Violência, publicado em 2017, "de cada 100 pessoas que sofrem homicídio no Brasil, 71 são negras. Jovens e negros do sexo masculino continuam sendo assassinados todos os anos como se vivessem em situação de guerra." (Instituto de Pesquisa Econômica Aplicada, p.32, 2017).

Observando a pintura vermelha de Henrique, atentamos para o título que a acompanha. Da mesma forma que "ver" não significa apenas enxergar, mas também testemunhar, "rever", significa não apenas voltar a ver, mas examinar cuidadosamente, corrigir, lembrar, reconhecer-se, deixar transparecer.

Ao centro da tela de Augusto há uma vela amarela, numa leitura possível, acesa para lansã. Em brasas pedimos por força e proteção em nossas vidas e batalhas. Também para termos coragem de enfrentar o mal, a morte e a exploração, o afastando nós. 


\section{A idéia de multiplicidade e antídotos históricos}

Desvencilhar corpos negros de heranças indignas, pecaminosas e vexatórias é apresentar nossos corpos como um instrumento para pensar, não apenas a cultura, mas conhecimentos filosóficos, históricos, sociais e medicinais. Uma forma de comunicação de cosmologias ancestrais que dispara múltiplos canais de significações não verbais.

A obra Cortejo (Fig. 4), de Gezsilene Oliveira (1998), de 2019, expõe elementos que chamaríamos de sincréticos. Uma bíblia, uma figa, Nossa Senhora, lansã, um terço, palo santo, oferendas, imagem ancestral, espadas de São Jorge, o sal grosso. Nas palavras da artista, publicadas em rede social:

Passei por processos intensos de conexão com a vida e a natureza nos últimos tempos. Um dos resultados foi essa instalação. A sincreticidade dos brasileiros nos processos de cura da alma é algo que me chama muita atenção e tem feito parte da minha história.

Mais do que a cor da pele o que nos une são os processos históricos, entre poder, saber e autoridade. Junto com as pluralidades e multiplicidade, a estratégia sincrética de se esconder dentro da matriz européia cristã é forma de sobrevivência da religiosidade africana, e das entidades que insistem em cortar o Atlântico. As danças e os tambores, transpondo a incompreensão

Figura 4

Gezsilene Olivei-

ra, Cortejo, Instalação, s.d, 2019, fotografia: MC Muxima

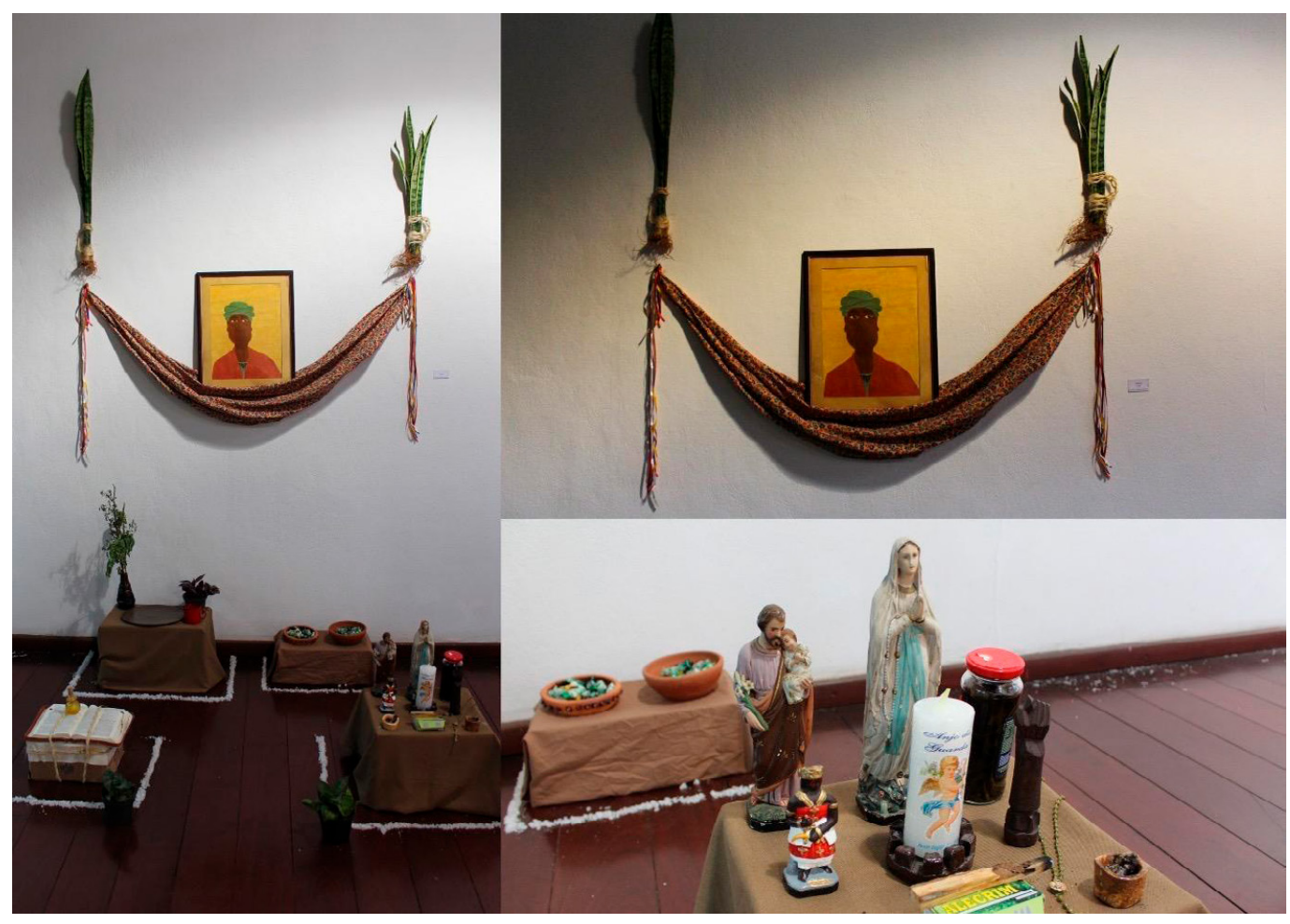


branca, e sustentando matrizes africanas em pleno encruzamento de uma mestiçagem de diversos povos de África, também são estratégicos na resistência negra. A dança iorubá, por exemplo, possui múltiplos canais comunicacionais. Para além do lúdico, ela articula crença, saberes filosóficos e sociais. Uma forma de permanência de cultos ancestrais, provocando a continuidade da memória de África latente em diáspora. Como aponta Gezsilene com ares de ritos, mas também como celebração, essa herança faz parte da nossa história. E é privilegiando a dimensão múltipla que encurtamos a distância entre uma proposta ideal de conceitualização de paradigmas e a presença massiva de uma determinada perspectiva dentro das instituições legitimadoras.

Durante a abertura da exposição, após a cena curta apresentada pela Companhia teatral Santa Corja, um forte cheiro invade a galeria, o incômodo expulsa os espectadores do espaço expositivo, como o texto curatorial já apontava "impossível de ignorar". Fitas zebradas, poucos dias de duração, uma performance que espanta o público. Processos de um racismo mascarado. Movimentos do mito da "democracia racial" que deixa em paz a consciência branca e aliena o restante. Ensinados a crer que no país miscigenado todos temos em comum a raiz africana, independente da cor da pele, como seria o racismo possível? Quais os signos que permitem nossas poéticas permanecerem? E quais são os que nos expulsam? Entre representações ou alegóricas ausências, as poéticas devem permanecer e curar. Estamos sendo ouvidos até que ponto?

Sabemos que quem cria a raça não é a pessoa racializada. Quem cria raça é o racista. Quem cria a raça é o colonizador. Quem cria a raça é o branco. A formulação da raça negra está, corroborada pela violência física e sustentada pela permuta entre liberdade e vida, no campo simbólico, tendo a escravidão como parte essencial dessa elaboração, que associa indivíduos diversos sob uma marca única. O sociólogo jamaicano Orlando Patterson (1940) e o filósofo e historiador camaronês Achille Mbembe (1957) concebem essa formulação de forma similar. Para Orlando a escravidão incorpora alguns recursos básicos, entre eles a rejeição do escravizado a seu passado, a mudança de nome, e a aceitação de uma nova condição, ora transformando o indivíduo em objeto, ora em animal (Patterson, 1982, p.52). Afim, Mbembe aponta que "de fato, a condição de escravo resulta de uma tripla perda: perda de um "lar", perda de direitos sobre seu corpo e perda de status político. Essa perda tripla equivale a dominação absoluta, alienação ao nascer e morte social (expulsão da humanidade de modo geral)." (Mbembe, 2016, p.131).

Humanidade dissolvida e a existência ressignificada em signo único. Logo, 
unidos, a partir da colonização e escravidão, por uma homogeneização que nos foi imposta, a arte produzida por nós, africanosbrasileiros, tem força, igualmente, no conjunto. Na transformação do ódio e da violência que se fez contra nós. A cura simbólica acontece na potência do diálogo entre artistas, obras e confluência entre o público. $O$ que parece ser repetitivo para os desavisados, repete para curar, repete para sarar as incontáveis chibatadas do passado, repete para mudar, repete para desinventar e humanizar a todos nós.

Em conversa entre artistas, nos recordamos de Lucas Caetano, residente em Juiz de Fora, afirmar: "quero que minha avó entenda do que estou falando.". Pois a produção africanabrasileira contemporânea vem

[...] na contramão dessa tendência da arte que cita a si própria e que, não raramente, gera produções ininteligíveis em termos conceituais, restringindo o acesso do grande público à plena apreensão dos significados contidos em tais obras impregnadas de uma erudição exacerbada, ensimesmadas, à margem da sociedade [...].

[...] A arte "deve ensinar alguma coisa, comunicar uma mensagem de vida, contribuir com o aprimoramento da humanidade". (Santos, p.194-195, 2016)

E humanizar você, eu, nossos mais velhos e nossos mais novos.

\section{Devolver}

Para os indígenas, os habitantes originais, não existia "Brasil", ou seja, "Brasil" é resultado de um conjunto de conceitos e histórias que imaginaram esse território com base no domínio colonial, que em essência já é estrangeiro. Assim,

a "ocupação colonial" em si era uma questão de apreensão, demarcação e afirmação do controle físico e geográfico - inscrever sobre o terreno um novo conjunto de relações sociais e espaciais. Essa inscrição (territorialização) foi, enfim, equivalente à produção de fronteiras e hierarquias, zonas e enclaves; a subversão dos regimes de propriedade existentes; (Mbembe, p.135)

O período histórico colonial teve sua forma de narrar e de controlar o saber, porém passagens que resistiam aos seus fundamentos, em outras palavras, que vinham atreladas a outras narrativas de vida, sempre existiram no curso histórico da colonização. Elas reposicionam o sentido da dominação, sem, necessariamente, superar sua influência. Por exemplo, do porto africano de Ouidah, no Daomé que corresponde hoje a Repúbli- 
ca do Benin, controlado por portugueses e ingleses durante um período do tráfico negreiro, saíram navios trazendo escravizados para o Brasil. No porto, os futuros escravos eram marcados de acordo com o comprador na chamada "Árvore do Esquecimento" (L'Arbre de l'Oubli). O nome do lugar, no entanto, deriva do ritual realizado em volta da árvore. Em seu em torno os homens deviam nove voltas e as mulheres sete. O ritual era, assim, um símbolo que concretizava a condição de escravizado daquelas pessoas, deixando para trás, a cada volta, identidade cultural e quaisquer outros vínculos de pertencimento. Diversamente, uma outra narrativa complementar diz que o rei Agadja (1673-1740) do Daomé plantou a "Árvore do Retorno" (L'Arbre du Retour) na Place de Zoungbodji, marcando o último adeus. Girando três vezes ao redor da árvore, os escravizados podiam garantir que seus espíritos retornassem à sua terra natal após a morte. (The Ouidah Museum of History). Muitos relatos do período do comércio de escravizados relatam a crença comum dos nascidos em África, de que, quando morressem, suas almas retornariam à África, o que de fato levou alguns deles a cometer suicídio como forma de voltar para casa.

Embora essa combinação, esquecimento e retorno, possa ter tido origens exteriores ao sentido do tráfico em si e, apesar de sua desordem lógica, podemos sugerir que o resultado final possa ser lido como uma representação sutil do comércio de escravos. Possivelmente confusos diante da aparente contradição das duas histórias, já que, se na "árvore do esquecimento" o escravizado perdia a memória e os vínculos com seu passado, podemos nos perguntar: como as almas retornariam para a terra de seus ancestrais após a morte? Pois bem, independente da precisão histórica desses relatos e mais do que uma interpretação literal, o que importa nesse exemplo não é a assertiva documentação de narrativas irrefutavelmente verídicas, mas a leitura possível que a existência delas traz para nós hoje. Desse modo, a contradição percebida entre a L'Arbre du Retour e L'Arbre de L'Oubli poderia simbolizar a resistência dos africanos contra o próprio sistema colonial, já que a lógica do sistema era obliterar as identidades dos sequestrados, mas a realidade histórica é que os escravizados e seus descendentes resistiram a essa obliteração conseguindo, com efeito considerável, manter não apenas traços das suas identidades, mas, sobretudo, o desejo de resgatá-las. (Law, 2008).

Assim, subvertendo os padrões de poder colonial, a recuperação de nossos saberes passa pelo entendimento do passado em África, para além da visão do colonizador, e a essência da vida construída em diáspora. Tomando para si o direito de ser "eu", e, dessa forma, trazendo nossas cosmovisões 
Figura 5

Maré, Brasil de

Verdade, impressão digital, 29 x $42 \mathrm{~cm}, 2019$, fotografia: MC Muxima

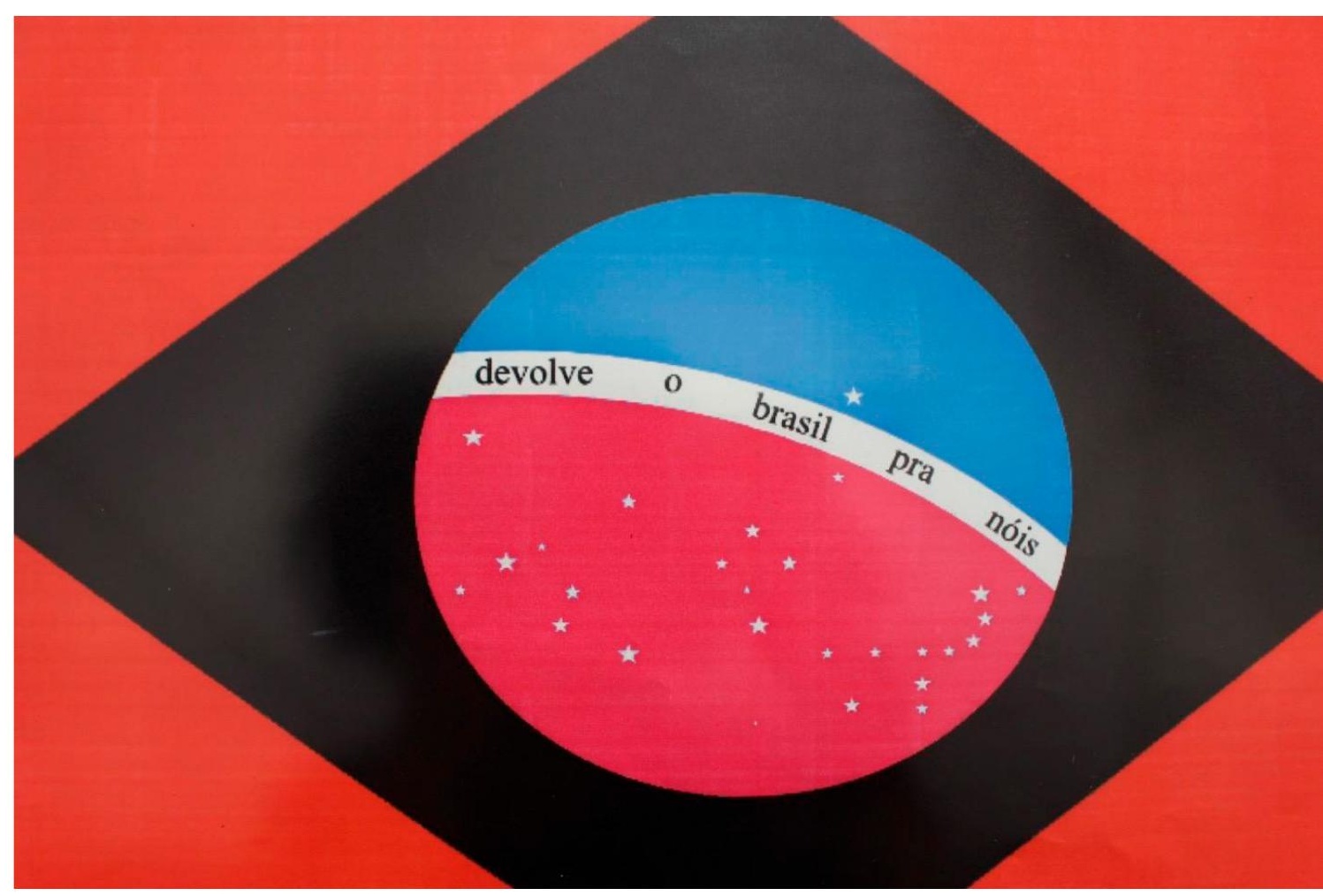

invisibilizadas dentro desse universal que parece ser sempre unicamente europeu.

Pensamos, da mesma forma, sobre a obra, presente na FRAGRANTE, com o título de Brasil de Verdade (Fig. 5), de 2019, criada por Maré (1996). A bandeira brasileira reproduzida com as cores vermelho e preto substituindo o verde e amarelo, ao centro o azul é trocado pelas cores da bandeira do movimento transgênero, que são o azul, o rosa e o branco, e a frase "devolve o brasil pra nóis" no lugar da ordem e do progresso. Logo, com a crítica de conceitos como "nação", acompanhando a proposta da exposição, o que vai ser devolvido e quem vai devolver? Vamos ler o verbo no presente do indicativo ou no imperativo? Ou seja, "devolver" é enviar, em nosso nome, essa ficção de nação de volta para quem a criou? Ou "devolver" é entregar, nas mãos de quem carregou nas costas escorridas de sangue, essa ficção de nação?

Sabemos que nomear é, também, tomar posse, portanto, nesse "Brasil", nós, quando ainda marcados, somos descartáveis. Mas e quando curados? Queremos permanecer nessa mesma terra imaginada "brasil" ou retornar para junto de nossos ancestrais? Lembrando, mais uma vez, que, mais do que uma interpretação literal, o que nos interessa são as leituras que essas 
ideias trazem para nós hoje.

O problema do pertencimento e como o elucidamos, quando entendemos a branquitude enquanto parte indispensável da questão, se torna mais profundo do que o simples direito a representatividade e valorização de nossas raízes.

Na entrada da exposição, a FRAGRANTE perguntou ao público: "Que nação? Quais corpos? Quem matou? Quem viveu?". E nós acrescentamos ao leitor: no fim das contas, qual é a humanidade que você procura?

\section{Referências}

BARRETO, Ana Claudia de Jesus. O Lugar do Negro em Juiz de Fora-MG: Segregação ambiental, espaço e raça. RePOCS, São Luís, v.15, n.30, Jul-Dez. 2018. Disponível em: <http://www.periodicoseletronicos.ufma.br/ index.php/rpcsoc/article/view/9689>. Acesso em: 03 Mar. 2020.

BORGES, G.; MANCINI, N. FRAGRANTE. Não publicado, 2019.

CARVALHO, Francione O.; SILVA, K. P. O preto ao cubo branco: 'dos pesos que se carrega'. ESTÚDIO 27, Artistas sobre outras Obras, Lisboa, v.10, n.27, p.77-85, Jul.-Set. 2019. Trimestral. Disponível em: <http://estudio. fba.ul.pt/E_v10_iss27.pdf>. Acesso em: 02 Mar. 2020.

DOS SANTOS, Márcio André. 80 tiros por "engano". Brasil de Fato, São Paulo, 15 Abr. 2019. Disponível em: <https://www.brasildefato.com. br/2019/04/15/artigo-or-80-tiros-por-engano>. Acesso em: 03 Mar. 2020.

GONZALEZ, Lélia. Racismo e sexismo na cultura brasileira. In: SILVA, L. A. et al. Movimentos sociais urbanos, minorias e outros estudos. Ciências Sociais Hoje, Brasília, ANPOCS n. 2, p. 223-244, 1983.

HALL, Stuart. Da Diáspora: Identidades e Mediações Culturais. Belo Horizonte: Editora UFMG, 2003.

HAUSER, Stuart T; KASENDORF, Eydie. Black and White Identity Formation. 2a. edição. Florida: Krieger Pub Co, 1983.

INSTITUTO DE PESQUISA ECONÔMICA APLICADA. Atlas da Violência. Rio de Janeiro, RJ, 2017, 75 p.

LAW, Robin. Commemoration of the Atlantic Slave Trade in Ouidah. Gra- 
dhiva, Paris, n.8, 2008. Disponível em: <https://doi.org/10.4000/gradhiva.1162>. Acesso em 21 Mar. 2020.

MOURA, Clóvis. Rebeliões da Senzala quilombos, insurreições, guerrilhas. 4a. edição. Porto Alegre: Mercado Aberto, 1988.

MBEMBE, Achille. Necropolítica biopoder soberania estado de exceção política da morte. Arte \& Ensaios, Rio de Janeiro, n.32, Dez 2016. Disponível em: <https://revistas.ufrj.br/index.php/ae/article/view/8993/7169>. Acesso em: 18 Mar. 2020.

. Crítica da Razão Negra. Lisboa: Antígona, 2014.

NEVES, Eustáquio. Ateliê do Artista: Eustáquio Neves. 2019. Websérie da Revista Bravo!. Disponível em: <https://www.youtube.com/watch?v=uuSJpNbiS6U>. Acesso em 03 Mar. 2020.

PAULINO, Rosana. O Processo Criativo de Rosana Paulino. 2014. Vídeo sobre o processo criativo da artista feito por Célia Antonacci. Disponível em: <https://vimeo.com/111885499>. Acesso em 03 Mar. 2020.

SANTOS, Renata Aparecida Felinto dos. A Construção da Identidade Afrodescendente por meio das Artes Visuais Contemporâneas: estudos de produções e de poéticas. 2016. 331f. Tese (Doutorado em Artes Visuais) Instituto de Artes, Universidade Estadual Paulista, São Paulo, 2016.

SOARES, Lucas. <https://lucassoares6.webnode.com/>. Acesso em 05 Mar. 2020.

TRIBUNA. Mascarenhas recebe a mostra "FRAGRANTE" Coletiva busca refletir sobre a presença da negritude em espaços de arte. Tribuna de Minas, Juiz de Fora, 04 Out. 2019. Disponível em: <https://tribunademinas. com.br/noticias/cultura/04-10-2019/mascarenhas-recebe-a-mostra-fragrante.html>. Acesso em: 03 Mar. 2020.

Recebido em 19 de abril de 2020 e aceito em 15 de junho de 2020.

Este é um artigo publicado em acesso aberto sob uma licença Creative Commons $(\mathbf{c c}) \mathbf{E Y}$ 